\title{
Cervical Spinal Nerve Root
}

National Cancer Institute

\section{Source}

National Cancer Institute. Cervical Spinal Nerve Root. NCI Thesaurus. Code C12893.

The initial segment of a nerve leaving the cervical spine. There are eight pairs of cervical roots, each consisting of two parts: the ventral (efferent motor) and the dorsal (afferent sensory) root which unite to form a sing le spinal nerve. All cervical nerves exit superiorly to their corresponding vertebrae with the exception of $C 8$, which exits inferiorly to the $C 7$ vertebra. 